\title{
Analysis of Hybrid Rechargeable Energy Storage Systems in Series Plug-In Hybrid Electric Vehicles Based on Simulations
}

\author{
Karel Fleurbaey, Noshin Omar, Mohamed El Baghdadi, Jean-Marc Timmermans, \\ Joeri Van Mierlo \\ Department of Electric Engineering and Energy Technology, Vrije Universiteit Brussel, Brussels, Belgium \\ Email: kfleurba@vub.ac.be
}

Received 30 May 2014; revised 1 July 2014; accepted 11 July 2014

Copyright (C) 2014 by authors and Scientific Research Publishing Inc. This work is licensed under the Creative Commons Attribution International License (CC BY). http://creativecommons.org/licenses/by/4.0/

(c) (i) Open Access

\section{Abstract}

In this paper, an extended analysis of the performance of different hybrid Rechargeable Energy Storage Systems (RESS) for use in Plug-in Hybrid Electric Vehicle (PHEV) with a series drivetrain topology is analyzed, based on simulations with three different driving cycles. The investigated hybrid energy storage topologies are an energy optimized lithium-ion battery (HE) in combination with an Electrical Double-Layer Capacitor (EDLC) system, in combination with a power optimized lithium-ion battery (HP) system or in combination with a Lithium-ion Capacitor (LiCap) system, that act as a Peak Power System. From the simulation results it was observed that hybridization of the HE lithium-ion based energy storage system resulted from the three topologies in an increased overall energy efficiency of the RESS, in an extended all electric range of the PHEV and in a reduced average current through the HE battery. The lowest consumption during the three driving cycles was obtained for the HE-LiCap topology, where fuel savings of respectively $6.0 \%, 10.3 \%$ and $6.8 \%$ compared with the battery stand-alone system were achieved. The largest extension of the range was achieved for the HE-HP configuration (17\% based on FTP-75 driving cycle). HP batteries however have a large internal resistance in comparison to EDLC and LiCap systems, which resulted in a reduced overall energy efficiency of the hybrid RESS. Additionally, it was observed that the HP and LiCap systems both offer significant benefits for the integration of a peak power system in the drivetrain of a Plug-in Hybrid Electric Vehicle due to their low volume and weight in comparison to that of the EDLC system.

\section{Keywords}

Plug-In Hybrid Electric Vehicle, Hybrid Energy Storage System, High Energy Battery, High Power Battery, Electrical Double-Layer Capacitor, Lithium-Ion Capacitor 


\section{Introduction}

The generation of energy in the society today is unsustainable from an environmental and economic point of view. The global economy is subjected to an increased price of fossil fuels and the public has shown a growing concern about environmental aspects. In the transport sector in particular, which accounts for $19 \%$ of the global energy use and $23 \%$ of the energy related $\mathrm{CO}_{2}$ emissions [1], internal combustion engines (ICE) based on fossil fuels dominate the market. Recent research in the automobile industry however has spurred the development of cleaner and more efficient technologies. Its main result is the increased use of (partially) electrically propelled vehicles such as Battery Electric Vehicles (BEVs), Hybrid Electric Vehicles (HEVs) and Plug-in Hybrid Electric Vehicles (PHEVs) [1]-[5]. PHEVs combine a Rechargeable Energy Storage System (RESS) with an ICE such that they can drive a certain distance purely electrical without being subjected to the drawback of a limited range. The future development of the various types of electric vehicles will however be highly dependent on the performance of the RESS [3] [5]-[7].

Currently, lithium-ion batteries are the preferred type of RESS for BEV and PHEV applications due to their high energy and power densities. They encompass a variety of technologies based on the materials that are used as anode, cathode and electrolyte. According to [4] [7]-[11], Lithium nickel cobalt aluminum oxide (NCA), Lithium iron phosphate (LFP), Lithium nickel manganese cobalt oxide (NMC) and Lithium manganese spinel oxide (LMO) show the highest potential for large scale application in BEVs and PHEVs (see Table 1). However, Burke and Omar et al. concluded respectively in [6] and [10] that none of the current batteries can yet fulfill the performance criteria proposed by the United States Advanced Battery Consortium (USABC). Critical aspects hereby are the cost, the lifetime and the energy content (thus the range of the electric vehicle). Moreover, battery design inherently incorporates trade-offs between these characteristics: for example, optimizing a battery for high power density results in the use of thin electrodes with a large surface area in order to make fast intercalation possible, while energy optimized batteries need thick electrodes in order to store the ions [5]-[11].

A number of hybrid RESS topologies have been proposed in the last decade in order to improve the performance of the RESS [12]-[19]. The most known dual source RESS combines an energy optimized (HE) battery with an Electrical Double-Layer Capacitor (EDLC) system. EDLC cells are characterized by a very high power density but have a low energy density. Their non-faradaic mechanism results in a low internal resistance, a high efficiency $(95 \%$ - 98\%) and a lifetime up to one million cycles [20] [21]. These characteristics make them an interesting candidate for use as Peak Power System (PPS) in a hybrid RESS. It is reported in [13]-[15] that the addition of an EDLC system to a Valve Regulated Lead-Acid (VRLA) battery results in an extension of the lifetime of the HE battery and enhances the power capabilities and energy efficiency of the RESS.

However, due to the superior energy density of lithium-ion batteries, most of the research for BEV and PHEV applications has focused on the combination of an energy optimized lithium-ion battery (HE) with an EDLC system. In [15]-[17], the authors found that the addition of an EDLC system in parallel to a lithium-ion battery results in an improvement in power capability of the hybrid RESS, in energy efficiency of the RESS and in cycle life of the HE battery. The low energy density and cell voltage of EDLCs however oblige the use of large amounts of cells connected in series, thus resulting in a large volume, weight and cost of the module.

The performance of the dual source RESS containing a HE battery and a power optimized (HP) lithium-ion battery is currently the subject of the European FP7 SuperLIB project [18] [19]. Its advantage over the HEEDLC topology is the higher cell voltage and higher energy content of the HP battery, what can result in a smaller and lighter PPS module. However, the cycle life of HP batteries is significantly lower than that of EDLC cells.

The recent commercialization of Lithium-ion Capacitors (LiCaps) also introduces the need for its investigation as PPS in a hybrid RESS. LiCap cells contain a porous activated carbon positive electrode, as conventional EDLCs, and a negative carbon electrode that contains pre-doped lithium ions, as lithium ion batteries (see Figure 1) [22]-[26]. The result is a hybrid storage device with characteristics in between lithium-ion batteries and EDLCs. Its main advantages with respect to EDLCs are its higher energy density (10 - $15 \mathrm{Wh} / \mathrm{kg}$ versus 5 $7 \mathrm{Wh} / \mathrm{kg}$ ) and higher operating voltage ( $3.8 \mathrm{~V}$ versus $2.7 \mathrm{~V}$ ), meaning that it is possible to reduce the amount of cells connected in series for certain high power applications [27]-[30].

In this paper, a model of a PHEV with series hybrid drivetrain topology is proposed in Matlab/Simulink environment. This model is used to analyze and compare the performance of different RESS architectures: the HE (non hybrid) battery stand-alone system, HE-EDLC, HE-HP and HE-LiCap. The focus of the RESS perfor- 
Table 1. Comparison of different lithium-ion technologies [11].

\begin{tabular}{|c|c|c|c|c|c|c|}
\hline & $\begin{array}{l}\text { Chemistry: } \\
\text { Neg/Pos Electrode }\end{array}$ & $\begin{array}{l}\text { Cell Voltage (V) } \\
\text { Max/Nom }\end{array}$ & $\begin{array}{l}\text { Capacity (mAh/g) } \\
\text { Neg/Pos Electrode }\end{array}$ & $\begin{array}{l}\text { Energy Density } \\
\text { (Wh/kg) }\end{array}$ & Cycle Life (Deep) & $\begin{array}{l}\text { Thermal } \\
\text { Stability }\end{array}$ \\
\hline NMC & Graphite/NiCoMnO ${ }_{2}$ & $4.2 / 3.6$ & $360 / 180$ & $100-170$ & $2000-3000$ & Fairly stable \\
\hline LMO & Graphite/Mn Spinel & $4.0 / 3.6$ & $360 / 110$ & $100-120$ & 1000 & Fairly stable \\
\hline NCA & Graphite/NiCoAlO ${ }_{2}$ & $4.2 / 3.6$ & $360 / 180$ & $100-150$ & $2000-3000$ & Least stable \\
\hline LFP & Graphite/Iron Phosphate & $3.65 / 3.25$ & $360 / 160$ & $90-115$ & $>3000$ & Stable \\
\hline LTO & Lithium Titanate/Graphite & $2.8 / 2.4$ & $180 / 110$ & $60-75$ & $>5000$ & Most stable \\
\hline
\end{tabular}

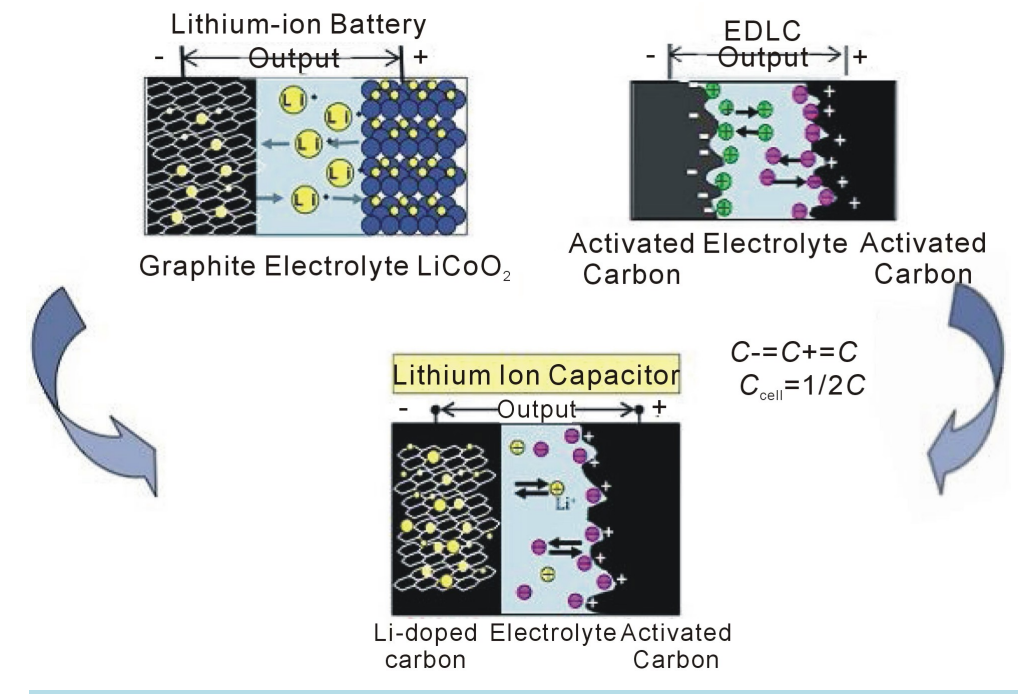

Figure 1. Mechanism of LiCaps [30].

mance analysis lies on the energy content, power capacity, energy efficiency, cycle life, volume and weight of the RESS. The case study and the proposed model of the Series PHEV are highlighted respectively in Section 2 and Section 3, while special attention to the modeling of the RESS is given in Section 4. The control strategy is explained in Section 5 and Section 6 contains the results and discussion of the simulations. The conclusions of the research are provided in Section 7.

\section{Case Study}

The performance of the different RESS is analyzed for a PHEV with a series drivetrain topology shown in Figure 2(a). The PHEV drives in all electric Charge Depletion (CD) mode as long as the State of Charge (SoC) of the battery is high enough, after which the ICE starts and the vehicle runs in Charge Sustaining (CS) mode. The advantage of the series hybrid configuration is the decoupling of the ICE from the wheels, meaning that it can run constantly in its most efficient operating area. The extra energy conversion of the mechanical power from the ICE to electrical power at the DC-bus however reduces the drivetrain efficiency [2].

The drivetrain of a Series PHEV with a hybrid RESS is shown in Figure 2(b). While driving in CD mode, the HE battery will act as the main energy source while the PPS provides/absorbs power during accelerations/ decelerations. The DC/DC converter in between the DC-bus and the PPS is introduced in order to allow controlling the power flows inside the hybrid RESS by regulating the power/current of the PPS with respect to the DC-bus voltage [16].

The considered vehicle in this study is the Chevrolet Volt. The specifications of this vehicle are shown in Table 2, where $m$ is the mass of the vehicle $(\mathrm{kg}), C_{d}$ the drag coefficient $(-), A_{f}$ the frontal surface $\left(\mathrm{m}^{2}\right), C_{r}$ the rolling resistance coefficient $(-), \delta_{J}$ the rotational inertia coefficient (\%), $\eta_{t}$ the efficiency of the transmission (\%), $P_{a u x}$ the mechanical auxiliary power $(\mathrm{W})$ and $P_{H V A C}$ the power of the heating, ventilation and air conditioning $(\mathrm{W})$. 
Table 2. Specification Chevrolet Volt [31].

\begin{tabular}{ccc}
\hline Parameter & Chevrolet Volt \\
\hline$m$ & Published Data & $1715 \mathrm{~kg}$ \\
$C_{d}$ & 0.287 \\
$A_{f}$ & Assumed Data & $2.16 \mathrm{~m}^{2}$ \\
& \\
$C_{r}$ & 0.010 \\
$\delta_{J}$ & 1.08 \\
$\eta_{t}$ & $95 \%$ \\
$P_{\text {aux }}$ & $700 \mathrm{~W}$ \\
$P_{\text {HVAC }}$ & $1857 \mathrm{~W}$ \\
\hline
\end{tabular}

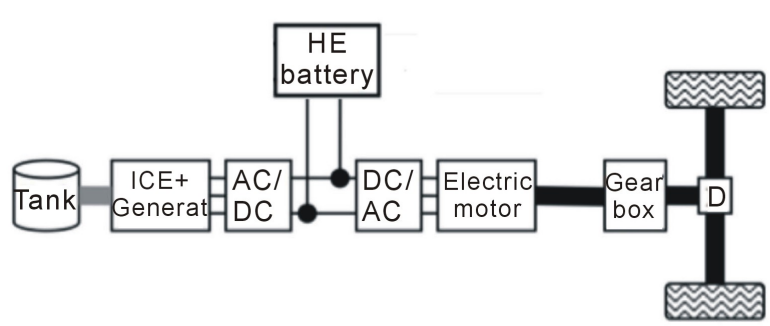

(a)

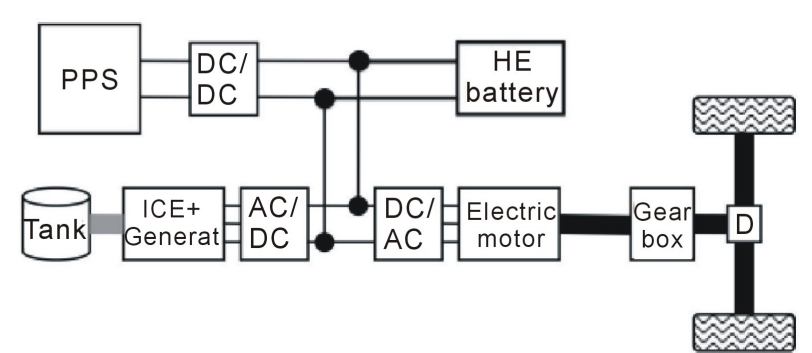

(b)

Figure 2. Drivetrain Series PHEV. a) Drivetrain Series PHEV [32]; b) Drivetrain Series PHEV with hybrid RESS.

\section{Series PHEV Model}

Regarding the modeling of vehicles, two different approaches can be distinguished in literature according to the direction of calculation of the power: the backwards or effect-cause method calculates the power in the direction opposite to the physical direction of the traction power. It starts by following the velocity profile of a specific driving cycle and computes the power that has to be delivered by the energy sources backwards through each component of the drivetrain. The main advantage of the backwards approach is its simplicity and fast computation time. The forward or cause-effect method computes the power according to the physical direction of the power flow, starting from the energy source through the drivetrain to the wheels. It uses a controller (cf. driver) that tries to follow a driving cycle and is preferred for real-time simulations as it allows obtaining best effort performances [32]-[35].

For this analysis, an efficient combined backward-forward model is designed to simulate the above-mentioned Series PHEV (see Figure 3). The main part of the program is written according to the backwards approach starting from the driving cycle (green) through the drivetrain (blue) to the energy sources (yellow) and controlled by the control strategy (red) - for reasons of simplicity and computation time [34]. The longitudinal dynamics are used to compute the wheel velocity and torque. Constant efficiencies for the transmission and converters and efficiency maps for the electrical motor, generator and ICE are used to characterize the components of the drivetrain. A forward model (purple) is introduced in order to take the maximum performance of the components into account. The forward subsystem is only activated at those moments that the performance of one of the components in the drivetrain is restricted, such that its effect on the computation time is limited.

An example of the influence of the forward part of the simulation is presented in Figure 4. Around timestamp 1110s, the battery stand-alone system cannot provide adequate power to reach the velocity of the driving cycle. The maximum achievable velocity of the PHEV is calculated. Starting around 1120s, the real achieved velocity of the vehicle is higher than that of the driving cycle in order to catch up the non-driven distance during the period 


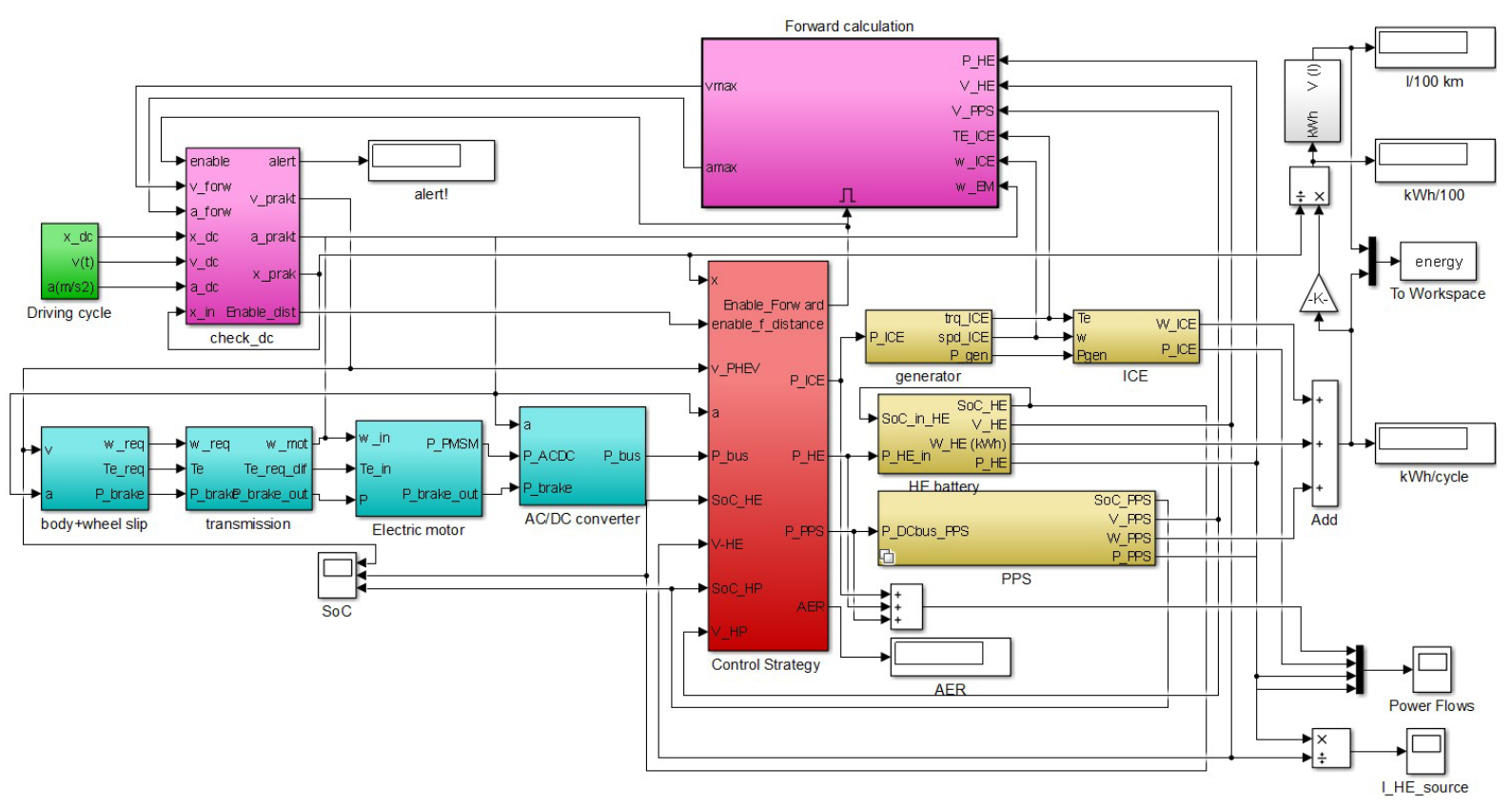

Figure 3. Combined backward/forward model of Series PHEV with hybrid RESS.

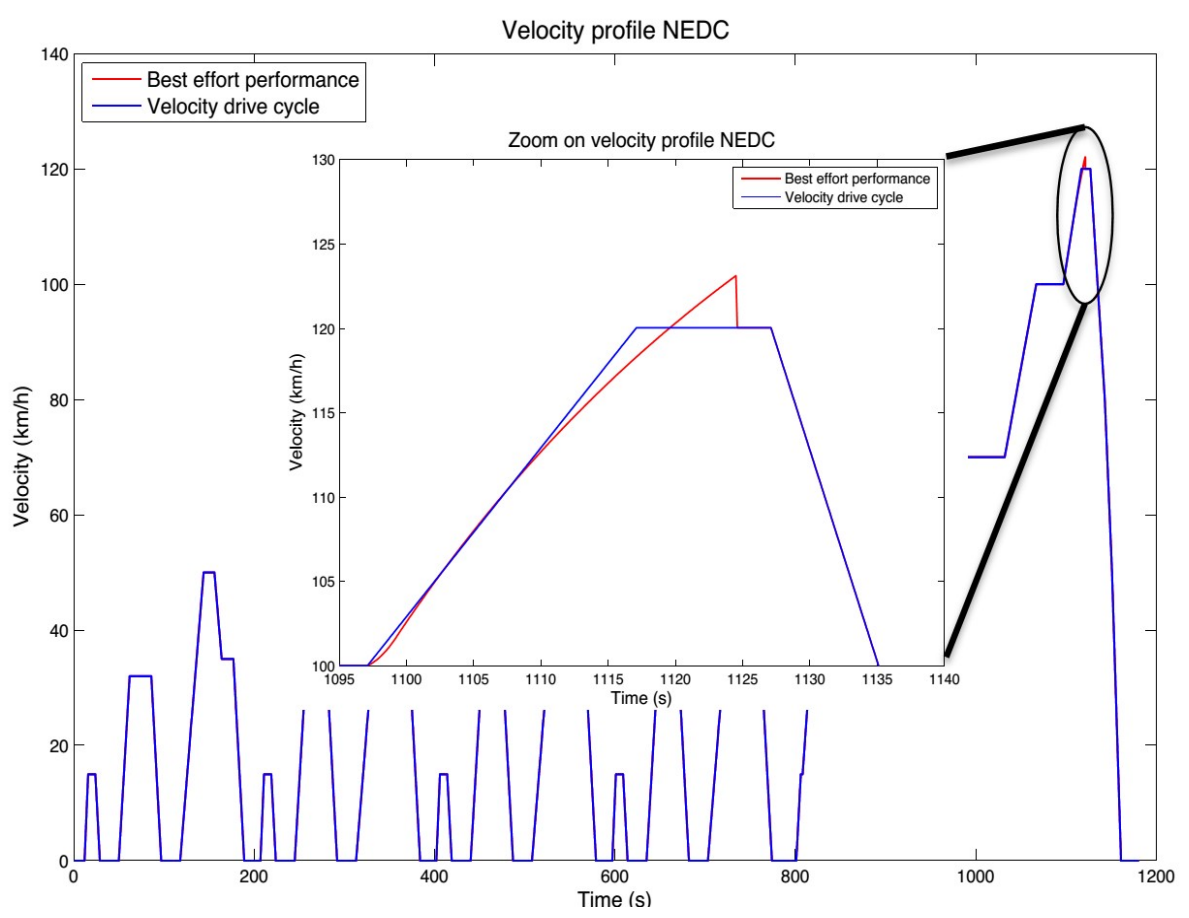

Figure 4. Influence forward approach.

that the driving cycle could not be followed.

\section{RESS Models}

\subsection{HE and HP Battery}

To model the batteries, the Rint-model with varying internal resistance in function of state of charge (SoC) and current demand is chosen (see Figure 5(a)). The main parameters of the HE and HP battery system are hig- 


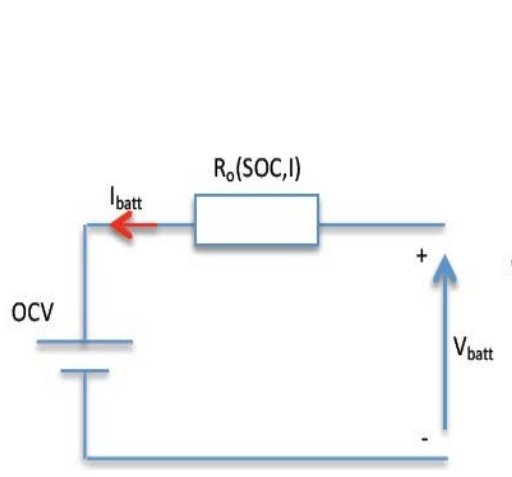

(a)

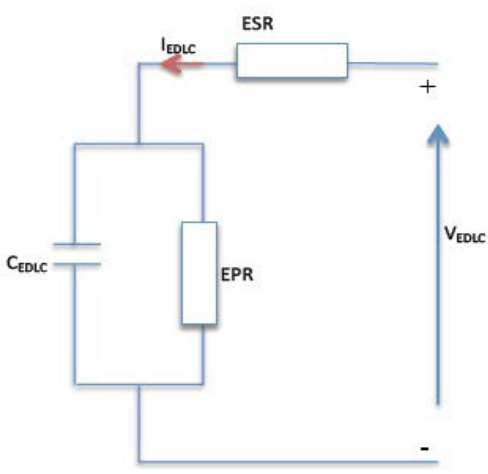

(b)

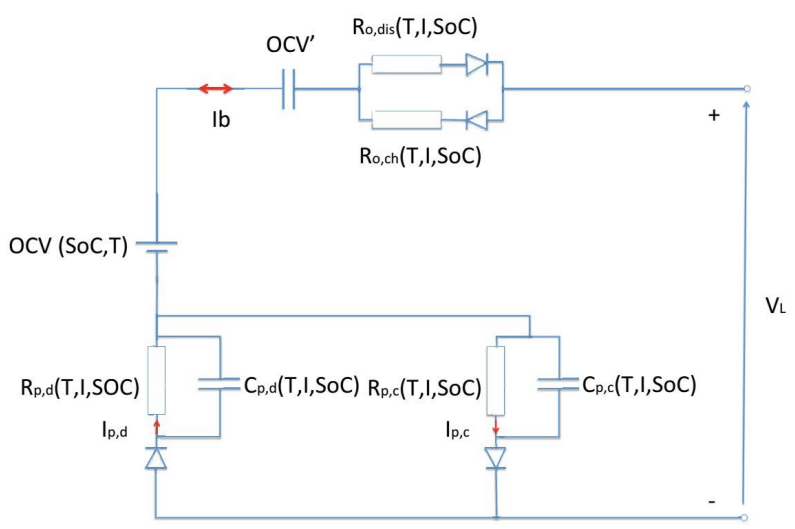

(c)

Figure 5. RESS models. a) Rint battery model; b) EDLC model; c) LiCap model [30].

hlighted in Table 3. Both the high energy (HE) and high power (HP) battery are lithium iron phosphate (LFP) batteries. The energy optimized LFP battery has a capacity of $45 \mathrm{Ah}$ and an energy density of $138 \mathrm{Wh} / \mathrm{kg}$. The power capability of the HE battery is limited by the maximum charge and discharge current rates of respectively 2C and 3C. The power optimized cell is characterized by a much lower reference capacity ( $7 \mathrm{Ah}$ ) but higher charge and discharge current rate up to 20C. The HE and HP battery systems contain both one string of 100 cells connected in series, resulting in a system voltage level of $330 \mathrm{~V}$ and an energy content of $14.8 \mathrm{kWh}$ for the HE battery system and $2.3 \mathrm{kWh}$ for the HP battery system, of which respectively $10.4 \mathrm{kWh}$ and $1.8 \mathrm{kWh}$ are usable due to the limitation of maximum Depth of Discharge (DoD).

\subsection{EDLC Model}

The equivalent circuit presented in Figure 5(b) describes the behavior of the EDLC cells and the parameters of the EDLC system are presented in Table 4. The Equivalent Series Resistance (ESR) denotes the ohmic resistance of the EDLC system, while the Equivalent Parallel Resistance (EPR) takes the static losses due to self-discharge into account.

The dimensioning of the EDLC system is based on the strategy proposed in [16] and shown in Figure 6. It is based on the Maxwell 125V heavy transport module [36]. The EDLC system is sized such that the kinetic energy of a full brake from $120 \mathrm{~km} / \mathrm{h}$ to $0 \mathrm{~km} / \mathrm{h}$ can be stored in the PPS, taking into account the losses in the drivetrain:

$$
E_{\text {tot }}=\frac{m * V_{\max }^{2}}{2} * \eta_{t} * \eta_{E M} * \eta_{D C / A C} * \eta_{D C / D C}
$$

The EDLC cells are controlled such that their voltage can vary from their maximum voltage $U_{E D L C \text {,max }}$ to $U_{E D L C, \max / 2}$, meaning that the EDLC cells can release or store $75 \%$ of their total energy content during operation: 
Table 3. HE and HP battery parameters.

\begin{tabular}{cccc}
\hline Parameter & HE Battery & HP Battery \\
\hline$m_{\text {batt }}(\mathrm{kg})$ & 171.8 & 44.4 \\
$V_{\text {batt }}\left(\mathrm{dm}^{3}\right)$ & 109 & 26 \\
$U_{n, \text { batt }}(\mathrm{V})$ & 330 & 330 \\
$C_{\text {batt, ref }}(\mathrm{Ah})$ & 35 & 7 & $20 / 20$ \\
\hline
\end{tabular}

Table 4. EDLC module characteristics [36].

\begin{tabular}{cc}
\hline Parameter & EDLC \\
\hline$m(\mathrm{~kg})$ & 121 \\
$V\left(\mathrm{dm}^{3}\right)$ & 1.02 \\
$C(\mathrm{~F})$ & 31.5 \\
$U_{n}(\mathrm{~V})$ & 250 \\
$U_{\min }-U_{\max }(\mathrm{V})$ & $136-272$ \\
$E S R(\mathrm{~m} \Omega)$ & 36 \\
\hline
\end{tabular}

$$
E_{E D L C}=\frac{C_{E D L C} *\left(U_{E D L C, \max }^{2}-U_{E D L C, \min }^{2}\right)}{2}
$$

The required total capacitance of the EDLC system can be calculated from Equation (2). Ideally, the cell capacitances are all identical such that

$$
N_{\text {cell }}=\frac{U_{\text {max }}}{U_{n, \text { cell }}}
$$

and

$$
C_{\text {cell }}=\frac{N_{\text {series }}}{N_{\text {par }}} * C_{E D L C}
$$

If the cell cannot provide the required current, the methodology should be performed again with an extra stack in parallel. Following the explained methodology resulted in the connection of two 125V modules in series.

\subsection{LiCap Model}

The model used to describe the behavior of the LiCap system is presented in Figure 5(c) and was proposed by Omar et al. in [30]. They presented a modified Freedom CAR first order model specifically designed for the 3300F prismatic LiCap cells of JSR Micro [37]. The hysteresis has been taken into account by separating the charge and discharge ohmic resistances and polarization circuits.

In order to allow comparing the performance of the HE-LiCap and HE-EDLC configurations in the Series PHEV, the LiCap system is sized such that its energy content is the same as that of the EDLC system:

$$
n_{\text {LiCap }}=\frac{2 * E_{E D L C, \text { sys }}}{C_{n, \text { LiCap }} * U_{n, \text { LiCap }}^{2}}
$$

Equation (5) resulted in the use of 59 LiCap cells in series. To obtain the mass and volume of the LiCap module, a packing factor of respectively 0.63 and 0.37 are used based on data released for one cell and for a module of 15 cells. The parameters of the LiCap system are shown in Table 5. 


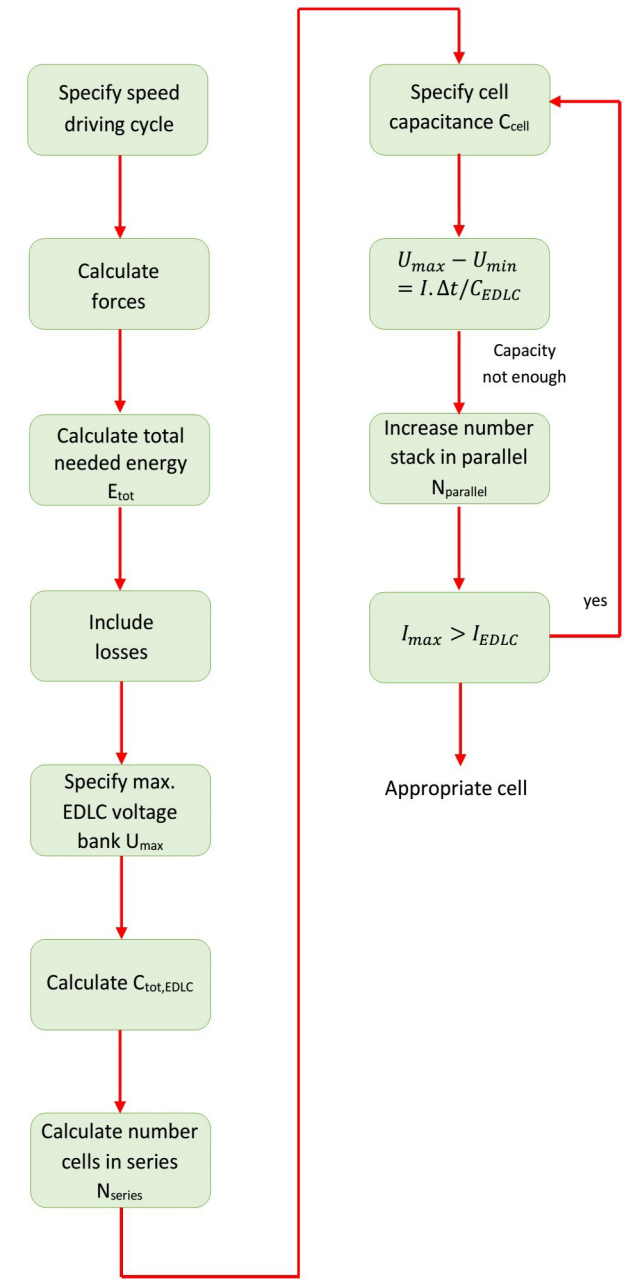

Figure 6. Dimensioning strategy EDLC system [16].

Table 5. LiCap parameters [37].

\begin{tabular}{cc}
\hline Parameter & LiCap \\
\hline$m(\mathrm{~kg})$ & 121 \\
$V\left(\mathrm{dm}^{3}\right)$ & 1.02 \\
$C(\mathrm{~F})$ & 31.5 \\
$U_{n}(\mathrm{~V})$ & 250 \\
$U_{\min }-U_{\max }(\mathrm{V})$ & $136-272$ \\
$R_{0, \text { licap }}(\mathrm{m} \Omega)$ & 36 \\
\hline
\end{tabular}

\subsection{Hybrid RESS Control}

\subsubsection{Hybrid RESS Control}

The idea behind hybridization of the RESS is to reduce the stress on the HE battery by adding an energy storage system that can provide the power peaks during acceleration. This distinction between peak power provided by the PPS and the moving average power supplied by the HE battery is made by the low pass filter (LPF) (see Figure 7). The LPF blocks the high frequency component of $P_{d c}$, resulting in the moving average power, which 


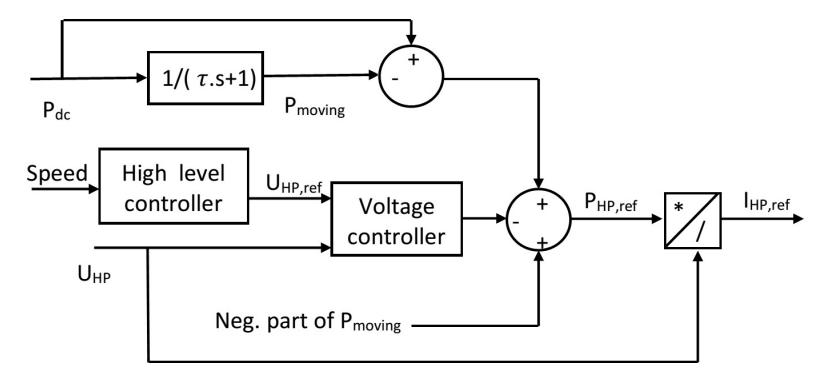

Figure 7. Control strategy hybrid RESS [14].

is provided by the HE battery:

$$
P_{\text {moving }}=\frac{1}{\tau * s+1} * P_{d c}
$$

where $\tau$ denotes the time constant (s) of the LPF. The peak power is defined as the difference between the required and the moving average power:

$$
P_{\text {peak }}=P_{d c}-P_{\text {moving }}
$$

The high level controller regulates the SoC of the PPS in function of the speed of the vehicle in order to ensure efficient operation of the PPS. The SoC of the PPS must for example be low at high velocities of the PHEV in order to allow absorbing all the regenerative braking energy during a possible brake event, while it must be high at low velocities in order to provide power during the next acceleration. A proportional controller compares the reference SoC with the actual SoC of the PPS and produces a power difference that needs to be supplied/ absorbed by the PPS. The SoC controller is slightly adjusted for the HE-HP hybrid architecture as the energy content of the HP battery is significantly higher than that of the EDLC and LiCap system (2.3 kWh versus respectively 292 and $294 \mathrm{Wh}$ ). It was opted to not relate the SoC of the HP with the velocity of the PHEV for this reason, but instead partially deplete the HP battery during CD mode in order to extend the AER of the vehicle. This practically means that the controller only becomes active if the SoC of the HP dropped below 30\% or rose above $90 \%$. This limitation is implemented in order to ensure safe operation of the battery and enlarge its cycle life.

\subsubsection{Optimization Time Constant}

The main design parameter of the control strategy is the time constant of the LPF. Implementing a large time constant results in a reduced HE battery stress but also requires a larger PPS. For the HE-EDLC case a time constant of 11s has been chosen. It allows full usage of the EDLC system within its voltage limits as can be seen in Figure 9 and is consistent with the time constant of 8s used by Cheng et al. in [14] for a similar configuration. The same time constant of 11s is also used for the HE-LiCap configuration as the LiCap system is dimensioned such that it contains the same amount of energy as the EDLC system.

The optimal time constant of the HE-HP configuration is obtained by analyzing the AER in function of the time constant. It is shown in Figure 8 that the time constant of 46 s resulted in the maximum AER of $47.9 \mathrm{~km}$ for the simulated PHEV during the NEDC.

\section{Results and Discussion}

Simulations with three different driving cycles have been performed: the New European Driving Cycle (NEDC), the Federal Test Procedure Driving Cycle (FTP-75) and the Highway Fuel Economy Driving Schedule (HWFET). The FTP-75 driving cycle represents typical urban driving behavior with a lot of accelerations up to a low velocity, while the HWFET describes highway driving conditions. The NEDC combines both driving conditions by implementing four repetitions of the ECE-15 Urban Driving Cycles with an Extra-Urban driving cycle. The simulation results are presented in Table 6 and Figure 9 illustrates the SoC level of the PPS and the distribution of the power flows over the different energy sources in the considered hybrid RESS during the NEDC.

It can be observed in Figure 9(a) and Figure 9(b) that the behavior of the HE-EDLC and HE-LiCap RESS are similar due to the use of the same time constant. The power provided by the HE battery is the moving aver- 
age of the required power, while respectively the EDLC system and the LiCap system provide the peak power. The effect of a larger time constant is illustrated in Figure 9(c) that represents the HE-HP RESS configuration. It is clearly visible that the power provided by the HE battery changes smoother over time, while the HP must provide the peak power during longer periods.

It is observed in Table 6 that the consumption of the PHEV is reduced due to hybridization of the RESS. The best result was obtained for the HE-LiCap system, where fuel savings of $6.0 \%, 10.3 \%$ and $6.8 \%$ were achieved for respectively the NEDC, the FPT-75 and the HWFET driving cycle. This result can be explained by the high energy efficiency of the HE-LiCap configuration and the low weight of the LiCap system. It can remarked that the energy efficiency of the HE-EDLC system is higher than that of the HE-LiCap system, but the final consumption of the PHEV is larger in the first case due to the higher mass of the EDLC system.

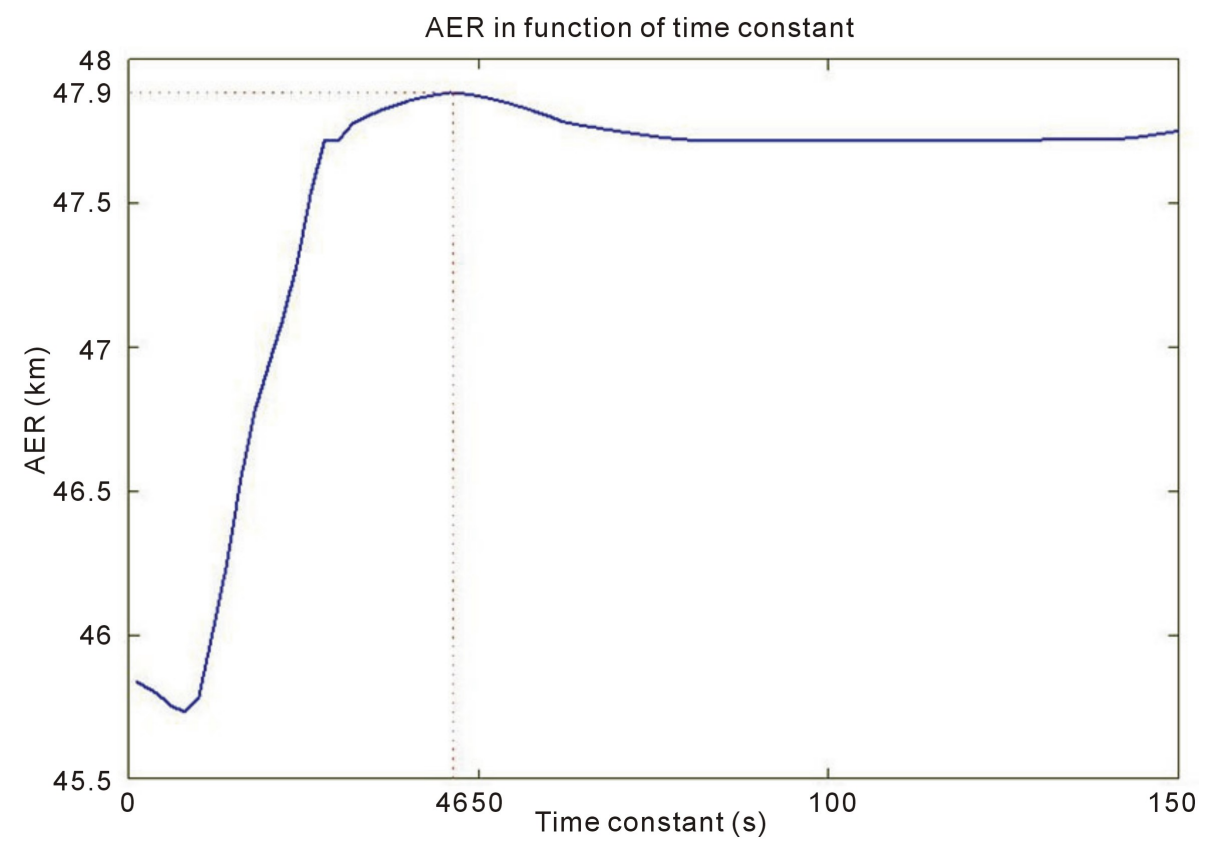

Figure 8. Optimization time constant HE-HP configuration.

Table 6. Simulation results.

\begin{tabular}{|c|c|c|c|c|c|c|c|c|}
\hline & $W_{d c} \quad(\mathrm{kWh})$ & $W_{d c} \quad(1 / 100 \mathrm{~km})$ & $\begin{array}{l}A E R \\
(\mathrm{~km})\end{array}$ & $\begin{array}{l}\text { Extension } \\
\text { AER (\%) }\end{array}$ & $\eta_{\text {RESS }} \quad(\%)$ & $I_{H E, R M S}(\mathrm{~A})$ & $V_{D C, \text { avg }}(\mathrm{V})$ & $\Delta V_{D C} \quad(\mathrm{~V})$ \\
\hline \multicolumn{9}{|l|}{ NEDC } \\
\hline $\mathrm{HE}$ & 2.63 & 2.70 & 42.5 & I & 86.5 & 38.9 & 322.3 & 55.1 \\
\hline HE-EDLC & 2.50 & 2.57 & 45.2 & 6 & 92.7 & 32.6 & 322.4 & 44.7 \\
\hline HE-HP & 2.52 & 2.59 & 47.9 & 13 & 90.3 & 26.7 & 322.6 & 24.6 \\
\hline HE-LiCap & 2.47 & 2.54 & 45.4 & 7 & 92.1 & 32.6 & 322.4 & 44.3 \\
\hline \multicolumn{9}{|l|}{ FTP-75 } \\
\hline $\mathrm{HE}$ & 4.17 & 2.64 & 43.8 & I & 84.2 & 41.3 & 322.9 & 49.3 \\
\hline HE-EDLC & 3.82 & 2.41 & 48.6 & 11 & 90.3 & 30.0 & 322.8 & 40.8 \\
\hline HE-HP & 3.91 & 2.47 & 51.3 & 17 & 86.5 & 22.4 & 322.7 & 16.4 \\
\hline HE-LiCap & 3.74 & 2.36 & 49 & 12 & 90.4 & 29.4 & 322.8 & 47.6 \\
\hline \multicolumn{9}{|l|}{ HWFET } \\
\hline $\mathrm{HE}$ & 2.77 & 1.88 & 61.1 & I & 88.7 & 53.9 & 318.8 & 56.9 \\
\hline HE-EDLC & 2.61 & 1.77 & 66.2 & 8 & 91.3 & 43.1 & 318.7 & 31.7 \\
\hline HE-HP & 2.65 & 1.80 & 70.0 & 15 & 88.3 & 35.4 & 318.7 & 17.0 \\
\hline HE-LiCap & 2.58 & 1.75 & 66.5 & 9 & 90.7 & 42.9 & 318.7 & 32.2 \\
\hline
\end{tabular}




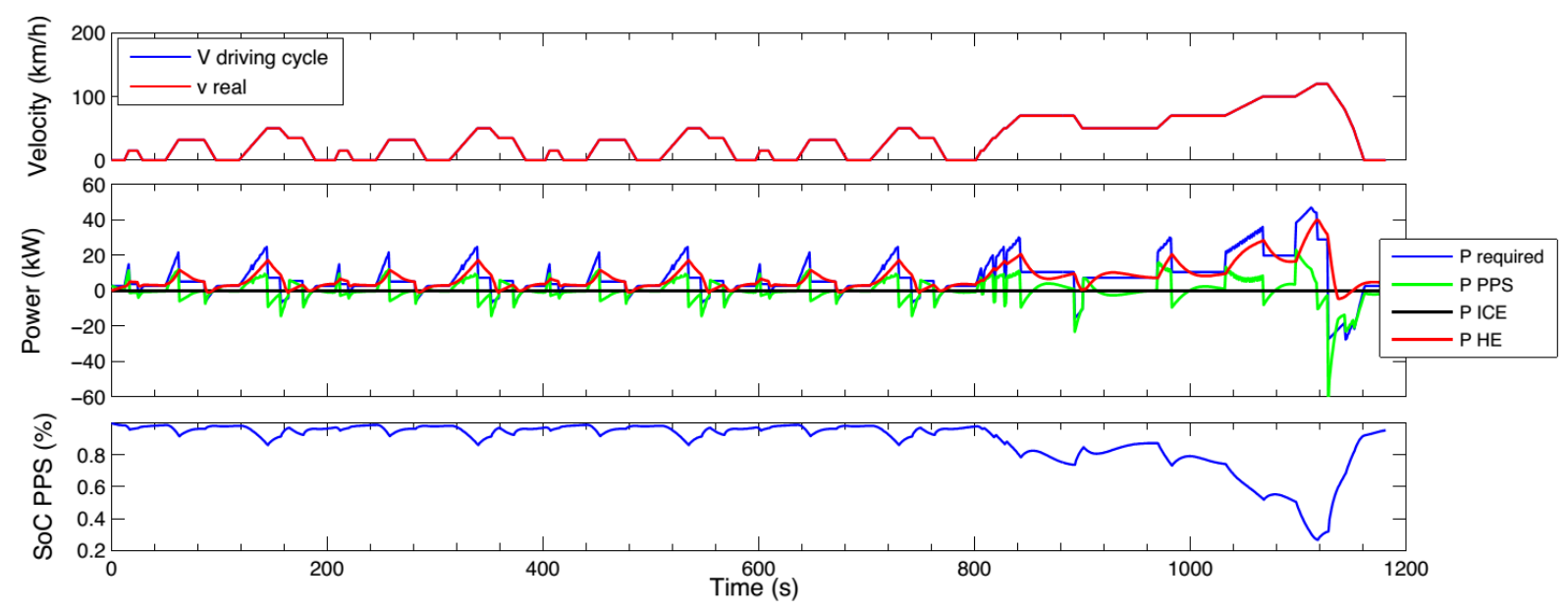

(a)

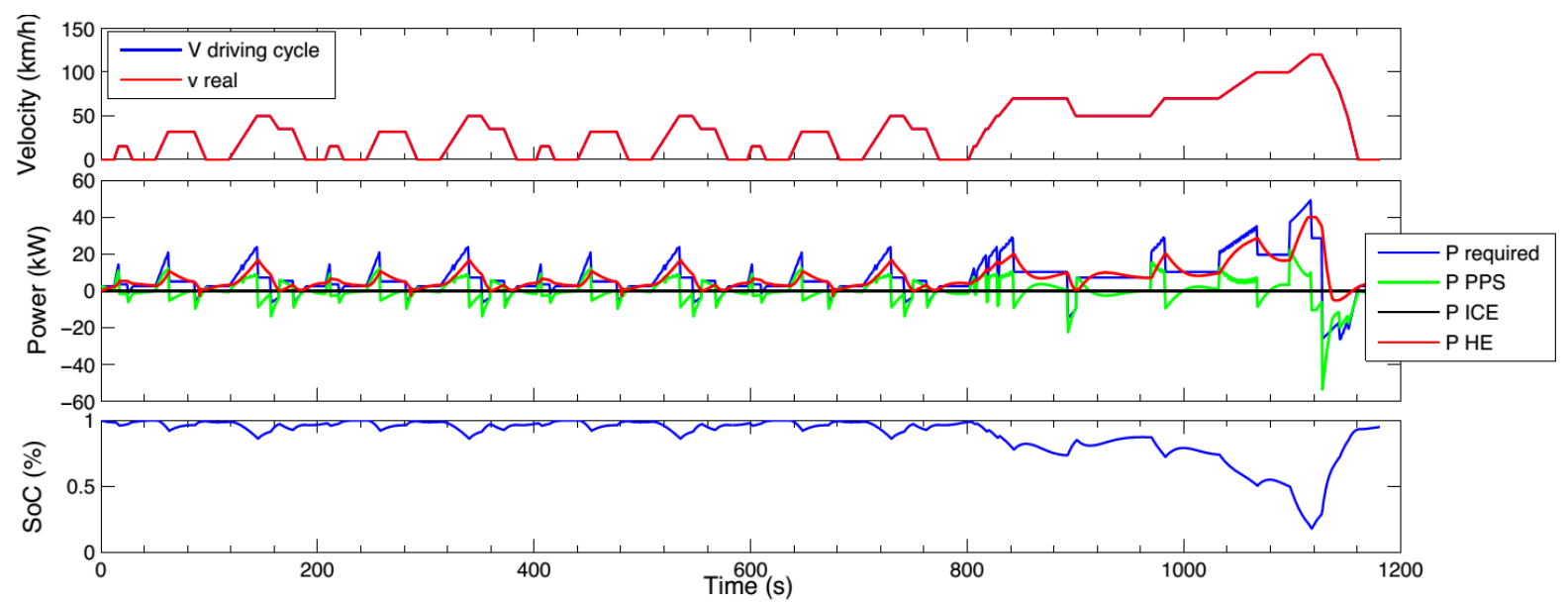

(b)

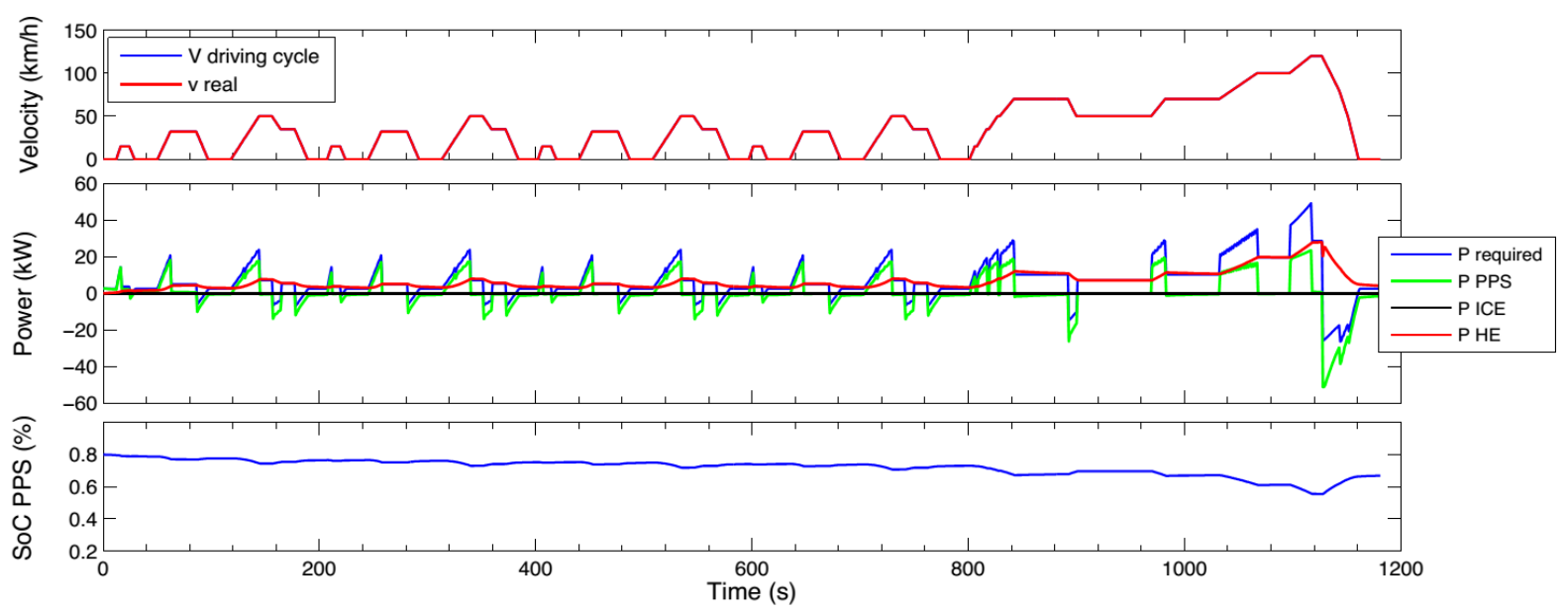

(c)

Figure 9. Power flows in the investigated hybrid RESS. a) Hybrid HE-EDLC configuration; b) Hybrid HE-LiCap configuration; c) Hybrid HE-HP configuration.

\subsection{Energy Content}

The AER of an electrically propelled vehicle is mainly linked to the energy content of its RESS. As mentioned 
in Section 4.1, the implemented HE battery system contains $14.8 \mathrm{kWh}$ of which $10.4 \mathrm{kWh}$ is usable. The obtained AER of the simulated series PHEV with this battery stand-alone system was $42.5 \mathrm{~km}$ for the NEDC. The increase in AER observed for the PHEVs with a hybrid RESS is mainly due to the increase in energy efficiency of the RESS (see Section 6.3). The 6.3\% extension in AER obtained in this research for the case study of the NEDC is in accordance with an extension of the AER of 7\% found in [16] for the same driving cycle. The significant increase in AER obtained for the HE-HP configuration is due to the (partial) depletion of the HP battery during CD driving mode (see Section 5.2.1). For example, during repeatedly driving of the NEDC, it was observed that the SoC of the HP battery dropped from $80 \%$ down to $45 \%$ at the moment that the ICE was started. The HP battery thus provided $0,8 \mathrm{kWh}$ of additional energy during CD mode. The largest extension of the AER was $17 \%$ obtained for the FTP-75 driving cycle, supporting the premise that peak shaving is more advantageous during urban driving.

\subsection{Power Capability}

The power capabilities of the proposed HE battery stand-alone system is limited by a $3 \mathrm{C}$ maximum discharge current rate, which results in a maximum discharge power of $44 \mathrm{~kW}$ :

$$
P_{H E \text {, } \max }=U_{H E, n} * I_{H E, \text { max }}=U_{H E, n} * 3 C_{H E, \text { ref }}
$$

It was already presented in Figure 4 that the simulated Series PHEV could not always follow the velocity profile of the NEDC. The reasons are the limitation on the maximum available power as mentioned above and the implemented restriction on the maximum current slope of the HE battery $\left(\begin{array}{ll}1 / 10 & I_{\max }\end{array}\right)$. Simulations with the FTP-75 and HWFET showed the same performance restriction, which were mostly retrieved for the FTP-75 due to its frequent accelerations. The introduction of a PPS improved largely the power performance of the PHEV. The maximum available power of the different PPS can be estimated by:

$$
\begin{gathered}
P_{E D L C, \text { max }}=\frac{U_{n, E D L C}^{2}}{4 * E S R}=434 \mathrm{~kW} \\
P_{H P, \text { max }}=U_{H P, \text { max }} * 20 C_{H P, \text { ref }}=46 \mathrm{~kW} \\
P_{E D L C, \text { max }}=\frac{U_{n, \text { LiCap }}^{2}}{4 * R_{o, \text { LiCap }}}=232 \mathrm{~kW}
\end{gathered}
$$

The restrictions found for the battery stand-alone system were not observed anymore after the implementation of the PPS.

\subsection{Energy Efficiency}

The energy efficiency of an energy storage system is normally defined as the ratio of the energy provided by the source during discharge over the energy required to charge the source up to the same SoC:

$$
\eta_{e}=\frac{\int_{t_{\text {begin }}}^{t_{\text {end }}} U_{R E S S, d i s} * I_{R E S S, d i s} * \mathrm{~d} t}{\int_{t_{\text {begin }}}^{t_{\text {end }}} U_{\text {RESS,ch }} * I_{R E S S, c h} * \mathrm{~d} t}
$$

In order to allow a fair comparison between the battery stand-alone system and the hybrid RESS, that also contains a PPS and a DC/DC converter in between the PPS and DC-bus, Equation (13) has been used in this research to denote the energy efficiency of the RESS:

$$
\eta_{e}=\frac{\int_{t_{\text {start }}}^{t_{\text {end }}} P_{\text {tot }} * \mathrm{~d} t-\int_{t_{\text {start }}}^{t_{\text {end }}} P_{D C} * \mathrm{~d} t}{\int_{t_{\text {start }}}^{t_{\text {end }}} P_{\text {tot }} * \mathrm{~d} t}
$$

where $P_{\text {tot }}$ represents the total power delivered by the different energy sources $(\mathrm{kW})$ and $P_{D C}$ denotes the power demand at the DC-bus $(\mathrm{kW})$. Figure 10 shows the decrease of the energy efficiency for the HE battery stand-alone system in function of the applied current. The course of the plotted curve can be explained by the 


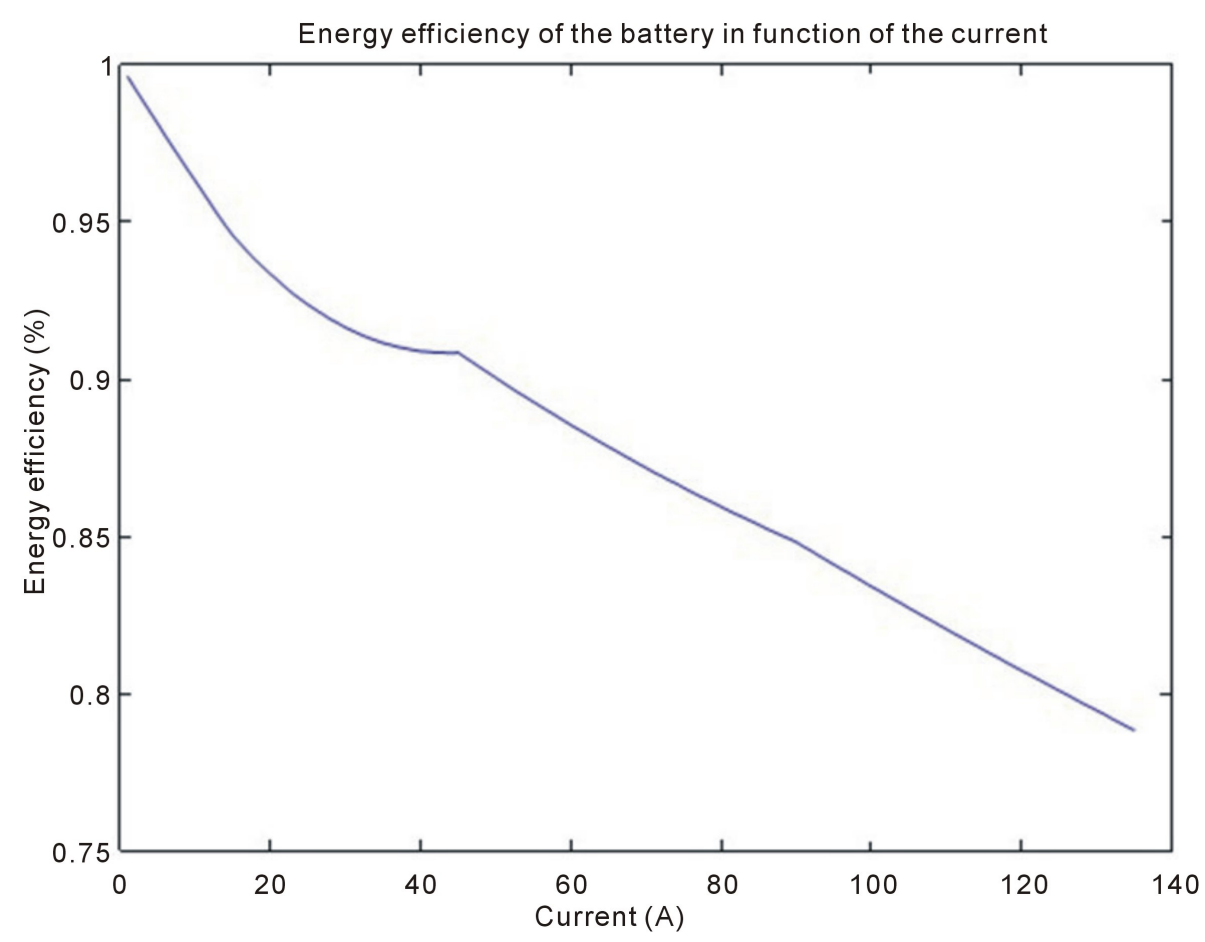

Figure 10. Energy efficiency of HE battery in function of current.

quadratic increase of the losses in function of the current.

$$
P_{\text {dis }}=R_{o, H E} * I^{2}
$$

Hybridization of the RESS has thus the advantage that the HE battery, which is characterized by a relatively large internal resistance in comparison to the PPS, is subjected to less peak powers (see the RMS current of the HE battery in Table 6). The consequence is a significant reduction of the losses in the HE battery and the appearance of losses in the DC/DC converter and the PPS.

It was observed that the obtained energy efficiencies of the hybrid RESS for the different driving cycles were higher than those of the battery stand-alone system for all three driving cycles, except in case of the HE-HP configuration during the HWFET cycle. The HE-EDLC topology reached the highest energy efficiency of the studied configurations due to their low ESR. For the NEDC, FTP-75 and HWFET, an improvement of respectively $7 \%, 7 \%$ and $3 \%$ over the battery stand-alone system was observed. The slightly higher internal resistance of the LiCap compared to EDLCs system caused a small reduction in energy efficiency for the HE-LiCap configuration, while the larger internal resistance of the HP battery system resulted in a further decrease of the energy efficiency for the HE-HP topology. It was observed that the energy efficiency of the HE-HP dual source RESS even dropped below that of the battery stand-alone system in the case the HWFET cycle that is characterized by a relatively high and constant velocity. The beneficial effect of peak power shaving with the HP battery is thus limited and the added weight and extra losses in the DC/DC converter and the HP battery resulted in a higher consumption.

\subsection{Cycle Life}

One of the main benefits of hybridization of the RESS is the reduction of the HE battery stress, which results in an extension of the lifetime. An accurate theoretical analysis of the cycle life of the HE battery system however is very complex. The ageing of a battery system is affected by a number of parameters, such as temperature, DoD, charge and discharge current, etc. Some of these parameters cause temporary performance losses, while others can reduce the capacity of the battery permanently or even damage the cell. In order to make a statement on the magnitude of the life cycle extension, dedicated experiments should be performed. The simulation results showed the decrease in RMS current of the HE battery in the studied hybrid RESS topologies. For city driving 
behavior simulated with the FTP-75, the addition of the EDLC, HP and LiCap system resulted respectively in a reduction of the HE battery RMS current with $27 \%, 46 \%$ and $29 \%$. The large time constant used in the HE-HP configuration resulted in a stronger filtering of the power peaks and thus further reduction of the RMS current.

Du Pasquier et al. compared in [38] the lifetime of an EDLC cell, a lithium ion battery cell and a lithium ion capacitor cell with LTO as negative electrode. The devices were subjected to cycles of a $3 \mathrm{C}$ charge rate and a constant power discharge of $675 \mathrm{~W} / \mathrm{kg}$ until the stored energy reached $80 \%$ of its initial value. It is observed that the cycle life of the components using an activated carbon cathode is at least one or two orders of magnitude larger than that of the lithium ion battery. However, it has to be remarked that this study already dates from 2003 and that the LiCap cells used in this research contain a different negative electrode, making it impossible to draw conclusions based on the cited research.

The datasheet of the 125V Maxwell module [36] mentions that one million cycles can be reached before the capacity dropped below $80 \%$ of its initial capacity when charging and discharging the module at a current of 100A. The data released for the 3300F LiCap cells in [37] show that the capacity did not decrease below $90 \%$ of the initial capacity after 200000 cycles when cycling at a charge and discharge current of 200A. No specific data regarding cycle life of the used HP battery were available, but different studies confirmed that the cycle life of LFP batteries do net yet reach the target of the USABC of 5000 cycles until 100\% DoD [11] [38]. The cycle life of the battery can be enlarged by reducing the DoD. It was for example observed in [39] that the studied LFP battery reached 2600 cycles at $100 \%$ DoD and 34957 cycles at 20\% DoD.

It can thus be concluded from the reasoning above that the cycle life of HP lithium ion battery cells is significantly lower than that of EDLC and LiCap cells. However, an accurate comparison of the lifetime of the three considered PPSs for this usage in this specific application was not possible due to the gap in literature regarding the ageing of advanced energy storage components.

\subsection{Volume and Weight}

The volume and weight of the RESS are considered as key issues in the design of PHEVs and are shown in Figure 11 for the different hybrid topologies. The disadvantage of the HE-EDLC topology from the point of view of weight (EDLC system adds $120 \mathrm{~kg}$ ) and volume $\left(1.02 \mathrm{dm}^{3}\right)$ is clearly observable. The low nominal voltage of EDLC cells resulted in the requirement of a large amount of cells in series in order to reach the required energy content. Here, it should be noted that the nominal voltages of the EDLC system is $250 \mathrm{~V}$ in comparison to $330 \mathrm{~V}$ for the HP battery system and 195V for the LiCap system. Moreover, the assembly of the cylindrical EDLC cells is not as efficient as the assembly of pouch cells (HP battery) or prismatic cells (LiCap).

It can thus be concluded from Figure 11 that the weight and volume of the HP battery system and of the LiCap system offer significant advantages over the EDLC system from the integration point of view.

\subsection{DC-Bus Voltage}

Hybridization of the RESS also benefits the stability of the DC-bus voltage as demonstrated in Figure 12 and Table 6. It was observed that the average DC-bus voltage of the different systems was not affected significantly by hybridization of the energy storage system, while the variations of the DC-bus voltage were drastically reduced due to the implementation of a PPS. The DC-bus voltage for the HE battery stand-alone system varied with $55.1 \mathrm{~V}, 49.3 \mathrm{~V}$ and $56.9 \mathrm{~V}$ for the NEDC, FTP-75 and HWFET cycle respectively. This difference was reduced to $24,6 \mathrm{~V}, 16,4 \mathrm{~V}$ and $17,0 \mathrm{~V}$ for the HE-HP configuration during the same driving cycles. The same effect was noticed in smaller magnitudes for the HE-EDLC and HE-LiCap topologies due to smaller time constant of the LPF. The lower voltage drop over the HE battery results in a higher energy efficiency of the HE battery, a reduction of the heat development due to filtering of the peak currents and in a higher efficiency of the complete drivetrain.

\section{Conclusion}

In this paper, a comparative analysis of the performance of a HE battery stand-alone system with that of a HE-EDLC system, a HE-HP system and a HE-LiCap hybrid RESS is presented for a PHEV with series hybrid drivetrain topology. Therefore, a combined backwards-forward simulation model in Matlab Simulink was developed in order to assess the performance of the considered RESS at different driving behaviors. 


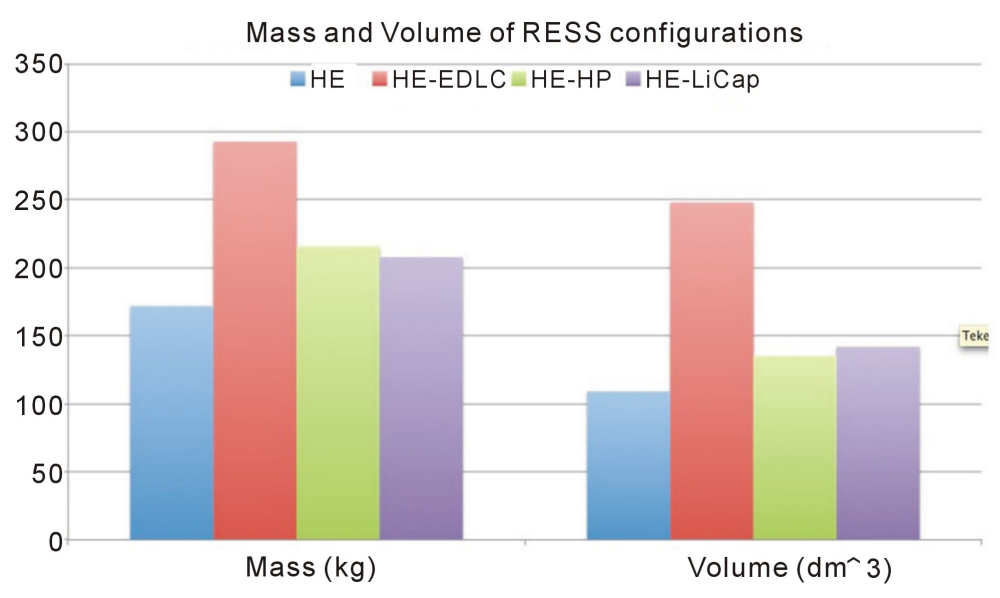

Figure 11. Volume and weight comparison of different RESS topologies.

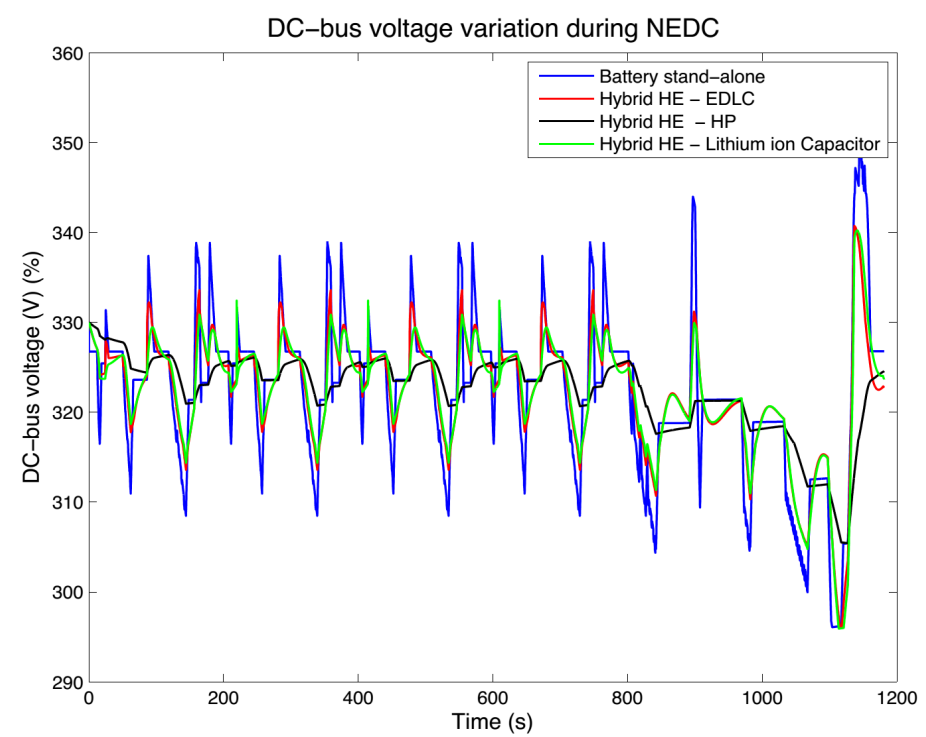

Figure 12. DC-bus voltage for different RESSS topologies.

It was found that the HE-HP configuration showed the highest potential with regard to AER extension. For the FTP-75 driving cycle, an increase of the AER with $17 \%$ was obtained. Moreover, the possibility of using a large time constant in the HE-HP configuration also resulted in a significant reduction of the HE battery RMS current and in a more stabilized the DC-bus voltage. The HE-EDLC topology proved to be the most beneficial topology from energy efficiency point of view with 92.7\%, 90.3\% and 91.3\% for the NEDC, FTP-75 and HWFET respectively. The obtained energy efficiencies of the HE-LiCap system were $92.1 \%, 90.3 \%$ and $90.7 \%$, but a significantly lower weight of the LiCap system resulted in an overall lower consumption of the series PHEV with the HE-LiCap system. Moreover, the LiCap system showed its advantage for usage in this application also from the point of view of the volume of the LiCap system, which can be considered as a key parameter in transport application. This advantage was also retrieved for the HE-HP hybrid configuration. Finally, a gap in literature with regard to cycle life analysis of different advanced energy storage systems was identified. Based on the datasheets of the different components, it was observed that the cycle life of the HP lithium ion battery is significantly lower than that of the EDLC and LiCap system, but performing an accurate lifetime analysis of the different components for use in this specific application was not possible.

It can thus be concluded that hybridization of the RESS resulted in an improved performance in terms of power capability, energy efficiency, all electric range and of battery stress. The different hybrid RESS all have 
their specific advantages, but the HE-LiCap topology resulted in the lowest consumption during the different simulated drive cycles due to their high energy efficiency and low weight.

\section{References}

[1] International Energy Agency (2009) Transport, Energy and $\mathrm{CO}_{2}$ : Moving toward Sustainability. OECD Publishing, Paris.

[2] Maggetto, G. and Van Mierlo, J. (2000) Electric and Electric Hybrid Vehicle Technology : A 2000/2010 Perspective. The Challenge for Cities in the 21st Century: Transport, Energy and Sustainable Development, DG TREN, Programme Thermie, Bilbao/Guggenheim.

[3] Van Mierlo, J., Timmermans, J.-M., Matheys, J. and Van den Bossche, P. (2006) Milieuvriendelijke Voertuigen. Vlaams Wetenschappelijk Economisch Congress, Brussels, 19-20 October 2006.

[4] Axsen J., Burke A. and Kurani K. (2008) Batteries for Plug-In Hybrid Electric Vehicles (PHEVs): Goals and the State of Technology Circa 2008. Institute of Transportation Studies, University of California, Davis, Research Report UCDITS-RR-08-14.

[5] International Energy Agency (2011) Technology Roadmap: Electric and Plug-In Hybrid Electric Vehicles. OECD Publishing, Paris.

[6] Axsen J., Kurani K.S. and Burke A. (2010) Are Batteries Ready for Plug-In Hybrid Buyers? Transport Policy, 17, 173-182. http://dx.doi.org/10.1016/j.tranpol.2010.01.004

[7] The Boston Consulting Group (2011) Batteries for Electric Cars: Challenges, Opportunities and the Outlook to 2020. www.bcg.com

[8] Omar, N., Verbrugge, B., Mulder, G., Van den Bossche, P., Van Mierlo, J., Daowd, M., et al. (2010) Evaluation of Performance Characteristics of Various Lithium-Ion Batteries for Use in BEV Application. IEEE Vehicle Power and Propulsion Conference, Lille, 1-3 September 2010, 1-6.

[9] Omar, N., Daowd, M., Van Den Bossche, P., Hegazy, O., Smekens, J., Coosemans, Th. and Van Mierlo, J. (2012) Rechargeable Energy Storage Systems for Plug-In Hybrid Electric Vehicles-Assessment of Electrical Characteristics. Energies, 5, 2952-2988. http://dx.doi.org/10.3390/en5082952

[10] Omar, N. and Van Den Bossche, P. (2011) Assessment of Performance of Lithium Iron Phosphate Oxide, Nickel Manganese Cobalt Oxide and Nickel Cobalt Aluminum Oxide Based cells for Using in Plug-In Battery Electric Vehicle Applications. IEEE Vehicle Power and Propulsion Conference (VPPC), Chicago, 6-9 September 2011, 1-7.

[11] Burke, A. and Miller, M. (2009) Performance Characteristics of Lithium-Ion Batteries of Various Chemistries for PlugIn Hybrid Vehicles. EVS24, Stavanger, 13-16 May 2009, 1-13.

[12] Pay, S. and Baghzouz, Y. (2003) Effectiveness of Battery-Supercapacitor Combination in Electric Vehicles. 2003 IEEE Power Tech Conference, Bologna, 23-26 June 2003.

[13] Omar, N., Van Mierlo, J., Verbrugge, B. and Van den Bossche, P. (2010) Power and Life Enhancement of BatteryElectrical Double Layer Capacitor for Hybrid Electric and Charge-Depleting Plug-In Vehicle Applications. Electrochimica Acta, 55, 7524-7531. http://dx.doi.org/10.1016/j.electacta.2010.03.039

[14] Cheng, Y., Van Mierlo, J., Van den Bossche, P. and Lataire, P. (2006) Super Capacitor Based Energy Storage as Peak Power Unit in the Applications of Hybrid Electric Vehicles. 3rd IET International Conference on Power Electronics, Machines and Drives, Dublin, 4-6 April 2006, 404-408. http://dx.doi.org/10.1049/cp:20060140

[15] Omar, N., Al Sakka, M., Daowd, M., Coosemans, T., Van Mierlo, J. and Van den Bossche, P. (2010) Assessment of Behavior of Active EDLC-Battery System in Heavy Hybrid Charge Depleting Vehicles. ESSCAP'10: Fourth European Symposium on Super Capacitors and Applications, Bordeaux, 21-22 October 2010.

[16] Omar, N., Daowd, M., Hegazy, O., Van den Bossche, P., Coosemans, T. and Van Mierlo, J. (2012) Electrical DoubleLayer Capacitors in Hybrid Topologies—Assessment and Evaluation of Their Performance. Energies, 5, 4533-4568. http://dx.doi.org/10.3390/en5114533

[17] Wu, Z., Zhang, J., Jiang, L., Wu, H. and Yin, C. (2012) The Energy Efficiency Evaluation of Hybrid Energy Storage System Based on Ultra-Capacitor and $\mathrm{LiFePO}_{4}$ Battery. WSEAS Transactions on Systems, 11, 95-105

[18] Omar, N., Coosemans, T., Martin, J., Sauvant-Moynot, V., Salminen, J., Kortschak, B., et al. (2012) SuperLib Project: Advanced Dual-Cell Battery Concept for Battery Electric Vehicles. EVS26, Los Angeles, 6-9 May 2012, 1-6.

[19] Omar, N., Fleurbaey, K., Kurtulus, C., Van den Bossche, P. and Van Mierlo, J. (2013) SuperLIB Project—Analysis of the Performances of the Hybrid Lithium HE-HP Architecture For Plug-In Hybrid Electric Vehicles. EVS27, Barcelona, 17-20 October 2013.

[20] Burke, A. (2007) R \& D Considerations for the Performance and Application of Electrochemical Capacitors. Electro- 
chimica Acta, 53, 1083-1091. http://dx.doi.org/10.1016/j.electacta.2007.01.011

[21] Kötz, R. and Carlen, M. (2000) Principles and Applications of Electrochemical Capacitors. Electrochimica Acta, 45, 2483-2498. http://dx.doi.org/10.1016/S0013-4686(00)00354-6

[22] Amatucci, G.G., Badway, F., Pasquier, A.D. and Zheng, T. (2001) An Asymmetric Hybrid Nonaqueous Energy Storage Cell. Journal of the Electrochemical Society, 148, A930-A939. http://dx.doi.org/10.1149/1.1383553

[23] Wang, Y., Luo, J., Wang, C. and Xia, Y. (2006) Hybrid Aqueous Energy Storage Cells Using Activated Carbon and Lithium-Ion Intercalated Compounds. Journal of the Electrochemical Society, 153, A1425-A1431. http://dx.doi.org/10.1149/1.2203772

[24] Wang, Y., Yu, L. and Xia, Y. (2006) Electrochemical Capacitance Performance of Hybrid Supercapacitors Based on $\mathrm{Ni}(\mathrm{OH})_{2}$ Carbon Nanotube Composites and Activated Carbon. Journal of the Electrochemical Society, 153, A743A748. http://dx.doi.org/10.1149/1.2171833

[25] Karthikeyan, K., Aravindan, V., Lee, S.B., Jang, I.C., Lim, H.H., Park, G.J., et al. (2010) A Novel Asymmetric Hybrid Supercapacitor Based on $\mathrm{Li}_{2} \mathrm{FeSiO}_{4}$ and Activated Carbon Electrodes. Journal of Alloys and Compounds, 504, $224-227$. http://dx.doi.org/10.1016/j.jallcom.2010.05.097

[26] Pasquier, A.D., Plitz, I., Gural, J., Menocal, S. and Amatucci, G. (2003) Characteristics and Performance of 500 F Asymmetric Hybrid Advanced Supercapacitor Prototypes. Journal of Power Sources, 113, 62-71. http://dx.doi.org/10.1016/S0378-7753(02)00491-3

[27] Gualous, H., Alcicek, G., Diab, Y., Hammar, A., Venet, P. and Adams, K. (2008) Lithium Ion Capacitor Characterization and Modelling. ESCAP'08: 3rd European Symposium on Supercapacitors and Applications, Rome, 6-7 November 2008.

[28] Omar, N., Al Sakka, M., Smekens, J. and Van Mierlo, J. (2013) Electric and Thermal Characterization of Advanced Hybrid Li-Ion Capacitor Rechargeable Energy Storage System. IEEE 4th International Conference on Power Engineering, Energy and Electrical Drives, Istanbul, 13-17 May 2013, 1574-1580.

[29] Omar, N., Daowd, M., Hegazy, O., Sakka, M., Coosemans, T., Van den Bossche, P. and Van Mierlo, J. (2012) Assessment of Lithium-Ion Capacitor for Using in Battery Electric Vehicle and Hybrid Electric Vehicle Applications. Electrochimica Acta, 86, 305-315. http://dx.doi.org/10.1016/j.electacta.2012.03.026

[30] Omar, N., Ronsmans, J., Firouz, Y., Monem, M.A., Samba, A., Gualous, H., et al. (2013) Lithium-Ion Capacitor-Advanced Technology for Rechargeable Energy Storage Systems. EVS27, Barcelona, 17-20 October 2013.

[31] General Motors (2013) Chevrolet Volt Specifications.

[32] Barrero, R., Coosemans, T. and Van Mierlo, J. (2009) Hybrid Buses: Defining the Power Flow Management Strategy and Energy Storage System Needs. EVS24, Stavanger, 13-16 May 2009.

[33] Van Mierlo, J. and Maggetto, G. (2004) Innovative Iteration Algorithm for a Vehicle Simulation Program. IEEE Transactions on Vehicular Technology, 53, 401-412. http://dx.doi.org/10.1109/TVT.2004.823534

[34] Wipke, K.B., Cuddy, M.R. and Burch, S.D. (1999) ADVISOR 2.1: A User-Friendly Advanced Powertrain Simulation Using a Combined Backward/Forward Approach. IEEE Transaction on Vehicular Technology, 48, 1751-1761. http://dx.doi.org/10.1109/25.806767

[35] Gao, D.W., Mi, C. and Emadi, A. (2007) Modeling and Simulation of Electric and Hybrid Vehicles. Proceedings of the IEEE, 95, 729-745. http://dx.doi.org/10.1109/JPROC.2006.890127

[36] Maxwell Technologies (2014) 125V Heavy Transportation Modules: Product Specifications.

[37] JSR Micro NV (2014) JSR Micro Prismatic Lithium Ion Capacitor. http://www.jsrmicro.be/en/lic_prismatic_cell

[38] Pasquier, A.D., Plitz, I., Gural, J., Badway, F. and Amatucci, G. (2004) Power-Ion Battery: Bridging the Gap between Li-Ion and Supercapacitor Chemistries. Journal of Power Sources, 136, 160-170. http://dx.doi.org/10.1016/j.jpowsour.2004.05.023

[39] Omar, N., Monem, M.A., Firouz, Y., Salminen, J., Smekens, J., Hegazy, O., et al. (2014) Lithium Iron Phosphate Based Battery-Assessment of the Aging Parameters and Development of Cycle Life Model. Applied Energy, 113, 1575-1585. http://dx.doi.org/10.1016/j.apenergy.2013.09.003. 
Scientific Research Publishing (SCIRP) is one of the largest Open Access journal publishers. It is currently publishing more than 200 open access, online, peer-reviewed journals covering a wide range of academic disciplines. SCIRP serves the worldwide academic communities and contributes to the progress and application of science with its publication.

Other selected journals from SCIRP are listed as below. Submit your manuscript to us via either submit@scirp.org or Online Submission Portal.
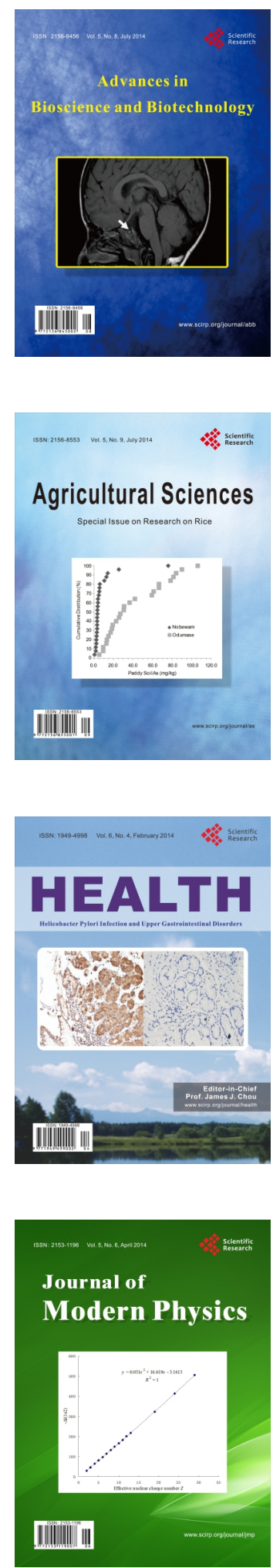
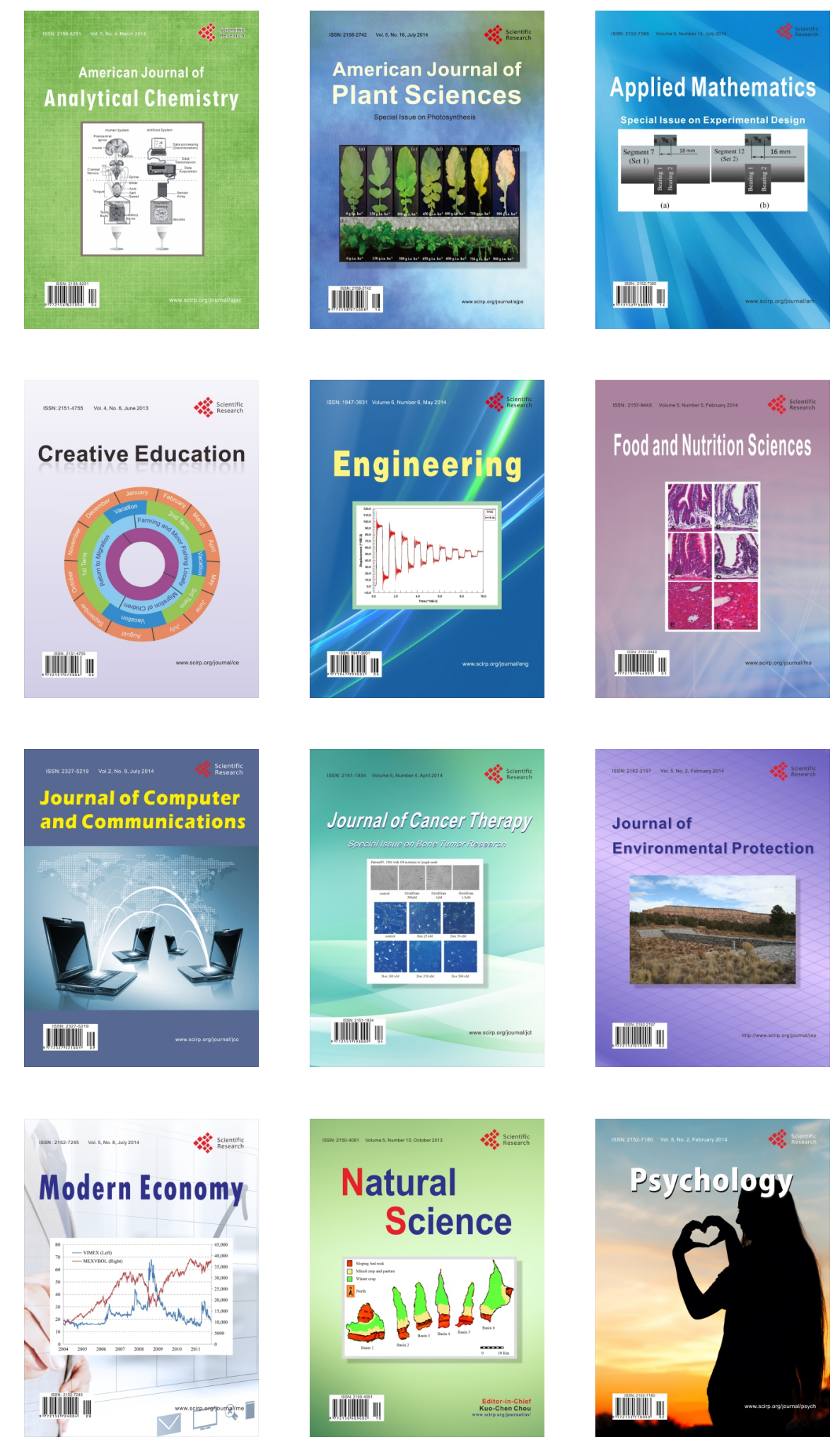